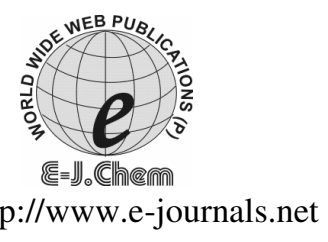

ISSN: 0973-4945; CODEN ECJHAO

E-Journal of Chemistry 2010, 7(2), 395-402

\title{
Spectrophotometric Method for the Determination of Drugs Containing Phenol Group by Using 2, 4- Dinitrophenylhydrazine
}

\author{
PADMARAJAIAH NAGARAJA* and ASHWINEE KUMAR SHRESTHA \\ Department of Studies in Chemistry, University of Mysore, \\ Manasagangotri, Mysore-57006, Karnataka, India. \\ saroj226@yahoo.com
}

Received 2 August 2009; Accepted 1 October 2009

\begin{abstract}
A spectrophotometric method has been proposed for the determination of four phenolic drugs; salbutamol, ritodrine, amoxicillin and isoxsuprine. The method is based on the oxidation of 2, 4- dinitrophenylhydrazine and coupling of the oxidized product with drugs to give intensely colored chromogen. Under the proposed optimum condition, beer's law was obeyed in the concentration range of $2.5-17,2-29,4-33$ and $5-30 \mu \mathrm{g} / \mathrm{mL}$ for salbutamol, ritodrine, amoxicillin and isoxsuprine respectively. The limit of detection (LOD) and limit of quantification (LOQ) were 0.2, 0.83, 0.09, $0.84 \mu \mathrm{g} / \mathrm{mL}$ and $0.66,2.79,0.3$ and $2.81 \mu \mathrm{g} / \mathrm{mL}$ in the same order. No interference was observed from common pharmaceutical adjuvants. The ringbom plots and low relative standard deviation assert the applicability of this method. The suggested method was further applied for the determinations of drugs in commercial pharmaceutical dosage forms, which was compared statistically with reference methods by means of $t$ - test and $F$ - test and were found not to differ significantly at $95 \%$ confidence level. The procedure is characterized by its simplicity with accuracy and precision.
\end{abstract}

Keywords: 2, 4- Dinitrophenylhydrazine, Salbutamol sulfate, Ritodrine $\mathrm{HCl}$, Amoxicillin trihydrate, Isoxsuprine $\mathrm{HCl}$, Spectrophotometry

\section{Introduction}

Salbutamol sulfate (SLB), ritodrine $\mathrm{HCl}$ (RTD), amoxicillin trihydrate (AMOX) and isoxsuprine $\mathrm{HCl}$ (IXP) are frequently prescribed biologically active compounds. Salbutamol sulfate and ritodrine is beta-2 agonist agent. SLB is used as a bronchodilator in the management of reversible airway obstruction. RTD is a uterine relaxant drug used to arrest premature labour. Amoxicillin trihydrate (AMX) is a broad spectrum antibiotic agent acting 
on both gram positive and gram negative bacteria. Isoxsuprin, a derivative of adrenaline, is an alpha receptor antagonist and beta receptor agonist, which is used as vasodilator and uterine relaxant.

Among the various methods available for the estimation of these drugs such as HPLC, Electrophoresis, Gas chromatography, Spectrophotometry method is still a preferred technique due to its simplicity and economy. Several colorimetric methods are available for the estimation of salbutamol ${ }^{1-6}$, ritodrine ${ }^{6-12}$, amoxicillin ${ }^{13-16}$ and isoxsuprine ${ }^{6,17-18}$.

The present work is an attempt to develop a rapid and sensitive method for the colorimetric estimation by 2, 4 dinitrophenylhydrazine (2, 4 DNP). 2, 4 DNP, also known as Brady's reagent, has been used for the characterization of aldehyde and ketones by hydrazone formation. We report here its application in the estimation of phenolic drugs. The method is based on the oxidation of 2, 4 DNP to produce diazonium cation, which couples with phenolic drugs to yield highly absorbing chromagen. Studies on different variables affecting the reaction were optimized. The developed method is simple, accurate and applicable for their determination in pharmaceutical formulations. All the above mentioned drugs are official in BP 2005.

\section{Experimental}

A JASCO (Model UVIDEC-610 UV-VIS spectrophotometry with $1 \mathrm{~cm}$ matched quartz cuvettes was used for all absorbance measurements.

\section{Reagents and solutions}

Analytical reagent grade chemicals and double distilled water were used throughout the experiment. Salbutamol sulfate (Cipla, India), ritodrine HCl (Duphar-Interfran Ltd, India), amoxicillin trihydrate (Sigma Aldrich, USA) and isoxsuprine $\mathrm{HCl}$ (Sigma Aldrich, USA) were procured and used as received. Stock solutions of each drug containing $100 \mu \mathrm{g} / \mathrm{mL}$ were prepared by dissolving $10 \mathrm{mg}$ of the respective drugs in $100 \mathrm{~mL}$ of water. The solutions were further diluted quantitatively according to their linearity range. The pharmaceutical preparations were purchased from a local market and analysed.

\section{Preparation of 2, 4-DNP reagents}

A $0.04 \% \mathrm{w} / \mathrm{v}$ and a $0.08 \% \mathrm{w} / \mathrm{v}$ of the reagent solution were freshly prepared by dissolving $0.04 \mathrm{~g}$ and $0.08 \mathrm{~g}$ of 2, $4 \mathrm{DNP}$ (SRL Chemicals, India) in $1 \mathrm{~mL}$ and $2 \mathrm{~mL}$ of concentrated $\mathrm{H}_{2} \mathrm{SO}_{4}$ respectively and diluting to $100 \mathrm{~mL}$ with water.

\section{Preparation of oxidizing agents}

For amoxicillin, a $0.15 \%$ w/v potassium periodate (The British Drug House, England) and for other drugs, a $4 \% \mathrm{w} / \mathrm{v}$ potassium iodate (Loba-Chemie, India) solution were prepared by dissolving suitable quantities in water.

\section{Preparation of tablet/capsule sample solution}

Twenty tablets of each drug was weighed, powdered and mixed thoroughly. Similarly, ten capsule of AMX were carefully evacuated, and mixed. A quantity equivalent to $10 \mathrm{mg}$ of each drug was transferred to $100 \mathrm{~mL}$ volumetric flask. The drugs were dissolved in water, shaken well, sonicated and made up to the volume with water. The resultant solutions were filtered and analysed as described under general procedure.

\section{General procedure}

Accurately measured suitable volume of SLB, RTD and IXP were transferred from stock solution to $10 \mathrm{~mL}$ volumetric flasks, which could be diluted quantitatively to obtain $2.5-17$, 
2-29 and 5-30 $\mu \mathrm{g} / \mathrm{mL}$ respectively. To each flask containing drugs in the order mentioned above, 1,2 and $1.5 \mathrm{~mL}$ of 2, $4 \mathrm{DNP}(0.04 \%)$ and 2,4 and $1.5 \mathrm{~mL}$ of $\mathrm{KIO}_{3}(4 \%)$ were added, which were made alkaline by adding $1 \mathrm{~mL}$ each of $\mathrm{NaOH}(10 \mathrm{~N})$. Similarly, for AMOX, an accurate quantity of drugs that could be diluted to $4-33 \mu \mathrm{g} / \mathrm{mL}$ was transferred in $10 \mathrm{~mL}$ volumetric flasks followed by addition of $1.5 \mathrm{~mL}$ of $2,4 \mathrm{DNP}(0.08 \%), 1.5 \mathrm{~mL}$ of $\mathrm{KIO}_{4}(0.15 \%)$ and $0.5 \mathrm{~mL}$ of $\mathrm{NaOH}(10 \mathrm{~N})$. The red color hence developed was further diluted to the volume with water.

\section{Results and Discussion}

\section{Spectral characteristic}

The absorption spectra of the reaction product of oxidized 2, 4 DNP with drugs show maximum absorption $\left(\lambda_{\max }\right)$ at 540, 510, 520 and $520 \mathrm{~nm}$ for SLB, RTD, AMOX and IXP respectively. The blank solution was slightly yellowish in color that had negligible absorbance at the $\lambda_{\max }$ in which the drugs were analysed. The thus formed color was stable for more than two hours. A temperature range of $20-30{ }^{\circ} \mathrm{C}$ is preferred for the reaction.

\section{Reaction sequence and stoichiometric relationship}

The 2, 4 DNP is oxidized by $\mathrm{KIO}_{3}$ or $\mathrm{KIO}_{4}$ to give diazonium cation that reacts with drugs by electrophilic substitution at the phenolic ring to give deep colored chromogens. The proposed reaction sequence for RTD is shown in Figure 1. The reaction sequence for other drugs is expected to follow the same sequence. The combining ratio was evaluated by the Job's method of continuous variation and molar ratio method, which shows that the complex formed between the drugs, SLB, RTD, IXP and AMX with 2, 4 DNP were 1:1, 1:2, 1:1 and 1:1 respectively. The plot of $\log$ [Absorbance] against Log [2, 4 DNP] and the drugs in limiting logarithmic method further confirmed the result. Figure 2 shows the continuous variation plot and limiting logarithmic plot for RTD.<smiles></smiles><smiles>[R10]CC(C)NCCc1ccc(O)cc1CCNC(C)C(O)c1ccc(O)c(N=Nc2ccc([N+](=O)[O-])cc2[N+](=O)[O-])c1</smiles>

Figure 1. Proposed reaction mechanism. 

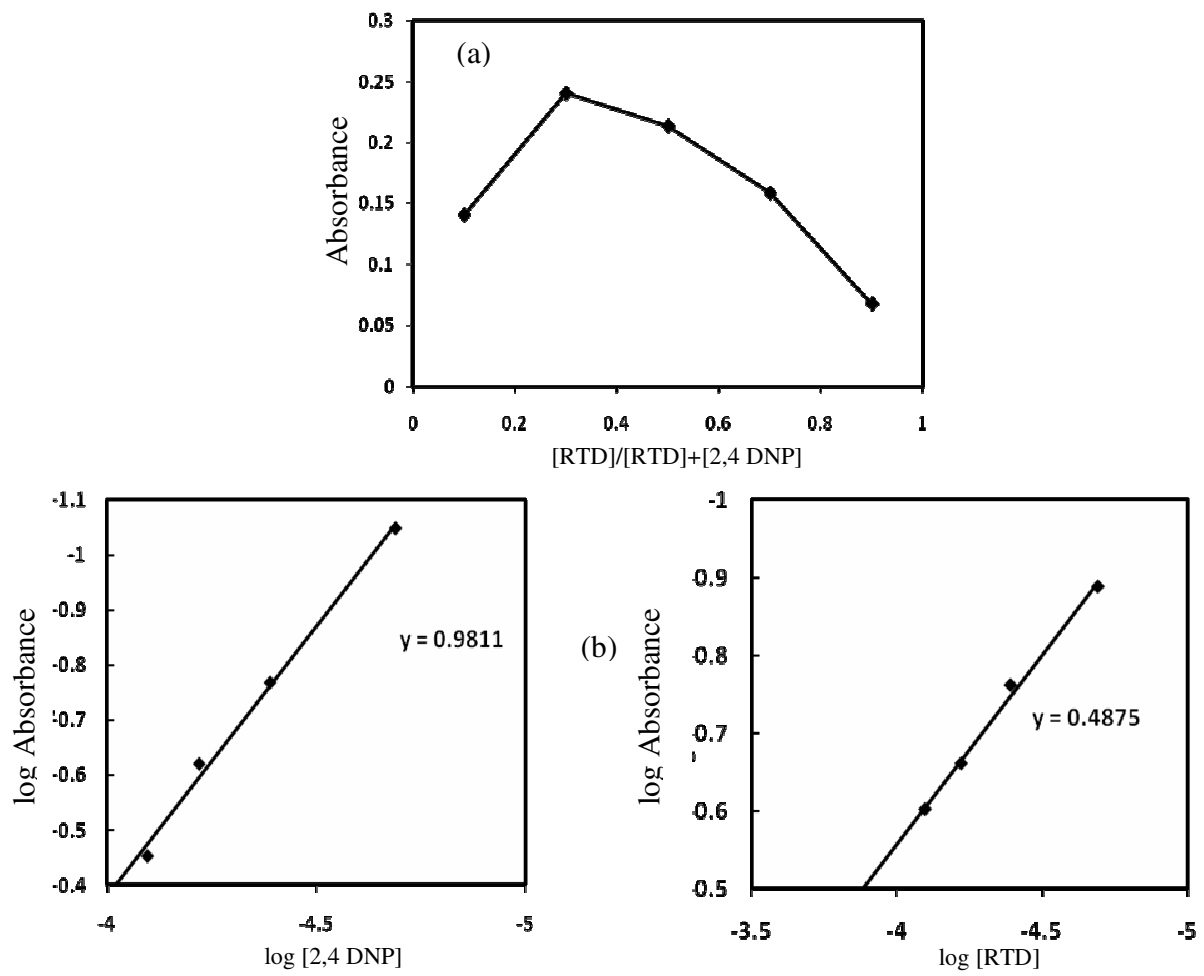

Figure 2.(a) Job's method of continuous variation plot and (b) Limiting logarthimic plot for the molar reactivity for RTD. The concentration of RTD and 2, 4 DNP is $2 \times 10^{-3} \mathrm{M}$.

\section{Optimum reaction condition}

By varying one and keeping other experimental parameters and the amount of drug constant, the effect of 2, 4-DNP, oxidizing agents and $\mathrm{NaOH}$ were studied. Maximum color intensity was obtained when $0.8-1.3,1.8-2.1,1.3-1.5 \mathrm{~mL}$ of $2,4 \mathrm{DNP}$ and 1.8-2.1, 3.7-4.2, 1.5-1.7 mL of iodate were added to SLB, RTD and IXP respectively. The amoxicillin produced more intense color when Potassium periodate was used as an oxidizing agent. The optimum quantity for amoxicillin was found to be 1.4-1.5 mL of 2, $4 \mathrm{DNP}$ and 1.3-1.6 mL of potassium periodate. Different concentrations of sodium hydroxide was used for maximum color development and was found that $1 \mathrm{~mL}$ of $10 \mathrm{~N} \mathrm{NaOH}$ was optimum except for AMX in which $0.5 \mathrm{~mL}$ of $10 \mathrm{~N} \mathrm{NaOH}$ was needed. During the analysis, the quantities of the reagents as mentioned in general procedure were taken.

\section{Validation of the proposed method}

\section{Linearity, detection and quantification limit}

Calibration graphs were constructed using standard solutions under optimum experimental condition. A linear relationship was observed between the absorbance and concentration of drugs from 2.5-17, 2-29, 4-33 and 5-30 $\mu \mathrm{g} / \mathrm{mL}$ for SLB, RTD, AMOX, and IXP respectively. The molar absorptivity and sandell's sensitivity for each drug were calculated from beer's law. The Ringbom plots demonstrated the range of 3-16, 5-26, 5-31 and 7-25 $\mu \mathrm{g} / \mathrm{mL}$ for SLB, RTD, AMOX and IXP respectively. The graph showed a negligible intercept, which was calculated by the least-square method's regression equation:

$$
\mathrm{A}=\mathrm{a}+\mathrm{bc}
$$


where, $\mathrm{A}$ is the absorbance of solution in a $1 \mathrm{~cm}$ cell, a is the intercept, $\mathrm{b}$ is the slope, and $\mathrm{c}$ is the concentration of the measured solution in $\mu \mathrm{g} / \mathrm{mL}$. The high molar absorptivities of the resulting colored solution indicated high sensitivity of the method. The limit of detection (LOD) and the limit of quantification (LOQ) value were determined using the formula

$$
\mathrm{LOD} \text { or } \mathrm{LOQ}=\mathrm{K} \mathrm{SD} / \mathrm{b}
$$

where, $\mathrm{K}=3$ for LOD and 10 for $\mathrm{LOQ}, \mathrm{SD}$ and $\mathrm{b}$ stand for standard deviation of the blank and slope, respectively. Repeatability and level of precision was tested by analyzing six replicate samples containing 13,15, 20 and $16 \mu \mathrm{g} / \mathrm{mL}$ and was found to be adequate for quantification of drugs as shown by their relative standard deviation. The confidence limits for the slope of line of regression and the intercept were computed using the relation, $b \pm t \mathrm{Sb}$ and $\mathrm{a} \pm \mathrm{tSa}$ at $95 \%$ confidence level. The results are shown in Table 1 . The error $(\mathrm{Sc})$ in the determination of a given concentration of drugs was defined by the expression where,

$$
S c=\frac{S y / x}{b}\left[1+\frac{1}{n}+\frac{\left(y o-\bar{y}^{2}\right.}{b^{2} \sum(x-\bar{x})}\right]^{2 / 2}
$$

$\bar{y}$ and $\bar{x}$ are the average values of the absorbance and concentration, respectively, for $\mathrm{n}$ standard samples. It is clear from the graph that the error is reached minimum when absorbance corresponding to about $10,15,13$ and $15 \mu \mathrm{g} / \mathrm{mL}$ of SLB, RTD, AMOX and IXP respectively, when the actual absorbance is equal to the average absorbance. The plot of error, Sc vs. concentration of RTD is shown in Figure 3.

Table 1. Optical characteristics and statistical data of the regression equation for the reaction

\begin{tabular}{|c|c|c|c|c|}
\hline \multirow[t]{2}{*}{ Parameters } & \multicolumn{4}{|c|}{ Optical Characteristic } \\
\hline & SLB & RTD & AMOX & IXP \\
\hline Colour & Reddish & Reddish & Reddish & Reddish \\
\hline$\lambda_{\max }, \mathrm{nm}$ & 540 & 510 & 520 & 520 \\
\hline Beer's Law range, $\mu \mathrm{g} / \mathrm{mL}$ & $2.5-17$ & $2-29$ & $4-33$ & $5-30$ \\
\hline Molar absorptivity, $\mathrm{L} / \mathrm{mol} / \mathrm{cm} \times 10^{4}$ & 2.19 & 0.741 & 1.0 & 8.04 \\
\hline Sandell's sensitivity, $\mu \mathrm{g} / \mathrm{cm}^{2}$ & 0.0263 & 0.0436 & 0.0418 & 0.0419 \\
\hline Limit of Detection, $\mu \mathrm{g} / \mathrm{mL}$ & 0.2 & 0.837 & 0.09 & 0.8451 \\
\hline Limit of quantification, $\mu \mathrm{g} / \mathrm{mL}$ & 0.66 & 2.79 & 0.3 & 2.817 \\
\hline Ringbom plot range, $\mu \mathrm{g} / \mathrm{mL}$ & $3-16$ & $5-26$ & $5-31$ & $7-25$ \\
\hline \multicolumn{5}{|l|}{ Regression Equation $(\mathrm{Y})^{\mathrm{a}}$} \\
\hline Slope (b) & 0.036 & 0.0252 & 0.0221 & 0.0275 \\
\hline Standard deviation of Slope $\left(\mathrm{S}_{\mathrm{b}}\right) \times 10^{-4}$ & 4.8 & 8.35 & 2.66 & 4.198 \\
\hline Intercept (a) & $0.0129-$ & 0.0125 & 0.0151 & 0.0424 \\
\hline Standard deviation of Intercept $\left(\mathrm{S}_{\mathrm{a}}\right) \times 10^{-3}$ & 5.84 & 14 & 5.0 & 7.88 \\
\hline Correlation Coefficient(r) & 0.9995 & 0.9993 & 0.9987 & 0.9993 \\
\hline Relative standard deviation $^{\mathrm{b}}$ & 0.185 & 0.349 & 0.223 & 0.236 \\
\hline$\pm \mathrm{ts}_{\mathrm{b}} \times 10^{-3}$ & 1.33 & 2.31 & 7.36 & 1.165 \\
\hline$\pm \mathrm{ts}_{\mathrm{a}}$ & 0.0152 & 0.0387 & 0.0138 & 0.02187 \\
\hline
\end{tabular}
of the proposed method. 


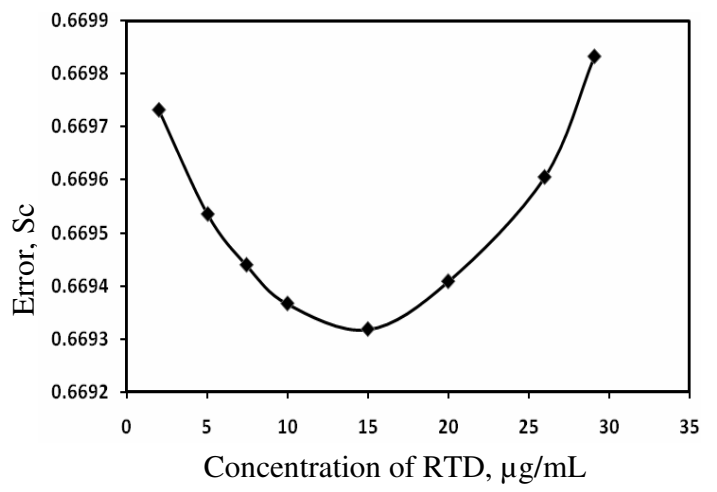

\section{Interference studies}

Figure 3. Plot of error in the determination of RTD

The effect of common excipients used in the pharmaceutical preparation were studied by analyzing synthetic sample solutions containing the quantity of drugs as mentioned in Table 2 in presence of 100 fold more concentration of each excipients. The tolerance limit was defined as the concentration which gave an error of $\pm 3.0 \%$ in the determination of drugs. The common excipients such as sodium chloride, starch, dextrose, lactose, talc, carboxymethyl cellulose, magnesium stearate, sucrose, had no effect in the analysis.

Table 2. Recovery of drugs from solution in presence of a 100 fold concentration of various additives used as excipients in formulation.

\begin{tabular}{lllll}
\hline \multicolumn{1}{c}{ Excipients } & \multicolumn{4}{c}{ Recovery \pm R.S.D $^{\mathrm{a}}$} \\
& SLB $^{\mathrm{b}}$ & RTD $^{\mathrm{c}}$ & AMOX $^{\mathrm{d}}$ & IXP $^{\mathrm{e}}$ \\
\hline Dextrose & $99.9 \pm 0.7$ & $99.9 \pm 0.5$ & $99.8 \pm 0.5$ & $99.8 \pm 0.4$ \\
Lactose & $100 \pm 0.2$ & $99.9 \pm 0.2$ & $99.9 \pm 0.4$ & $99.8 \pm 0.1$ \\
Sucrose & $99.9 \pm 0.5$ & $99.9 \pm 0.1$ & $99.8 \pm 0.2$ & $99.9 \pm 0.4$ \\
Starch & $99.9 \pm 0.1$ & $99.8 \pm 0.4$ & $99.9 \pm 0.1$ & $99.9 \pm 0.3$ \\
Talc & $99.8 \pm 0.4$ & $99.9 \pm 0.3$ & $99.9 \pm 0.4$ & $99.7 \pm 0.0$ \\
Carboxymethyl cellulose & $99.8 \pm 0.4$ & $99.8 \pm 0.5$ & $99.8 \pm 0.5$ & $99.8 \pm 0.3$ \\
Magnesium Sterate & $99.8 \pm 0.5$ & $99.7 \pm 0.7$ & $99.8 \pm 0.5$ & $99.7 \pm 0.5$ \\
Sodium Chloride & $100 \pm 0.1$ & $100 \pm 0.1$ & $100 \pm 0.2$ & $100 \pm 0.2$ \\
\hline of 3 determination, ${ }^{b}$ Concentration of SLB used $-10 \mu \mathrm{gg} / \mathrm{mL}^{c}{ }^{c}$ Concentration of RTD used $-15 \mu \mathrm{g} / \mathrm{mL}$,
\end{tabular}

\section{Precision studies}

The short term precision (intraday precision) of the drugs were evaluated by measuring 5 independent samples at 3 different concentration levels $(4.0,8.0,12.0 \mu \mathrm{g} / \mathrm{mL}$ for SBM, 10.0, 15.0, $20.0 \mu \mathrm{g} / \mathrm{mL}$ for RTD, 15.0, 20.0, $25.0 \mu \mathrm{g} / \mathrm{mL}$ for AMOX, and 15.0, 20.0, $25.0 \mu \mathrm{g} / \mathrm{mL}$ for IXP). Similarly, the assay for daily precision (interday precision) at the same concentration level was repeated for 5 consecutive days (Table 3 ). The available pharmaceutical dosage forms of the investigated drugs were analysed by the proposed method. The precision of the method was checked by taking six replicate measurements. The results obtained by the proposed and the reference methods for the dosage forms were compared statistically by means of $F$ - and $t$ - test and were found not to differ significantly at $95 \%$ confidence level. The reliability and accuracy of the proposed method were further ascertained through recovery studies using the standard addition method by adding different amount of standard drugs to the preanalyzed dosage forms such that the cumulative amount after adding the drugs did not exceed their linearity range (Table 4). 
Table 3. Intraday and interday precision data.

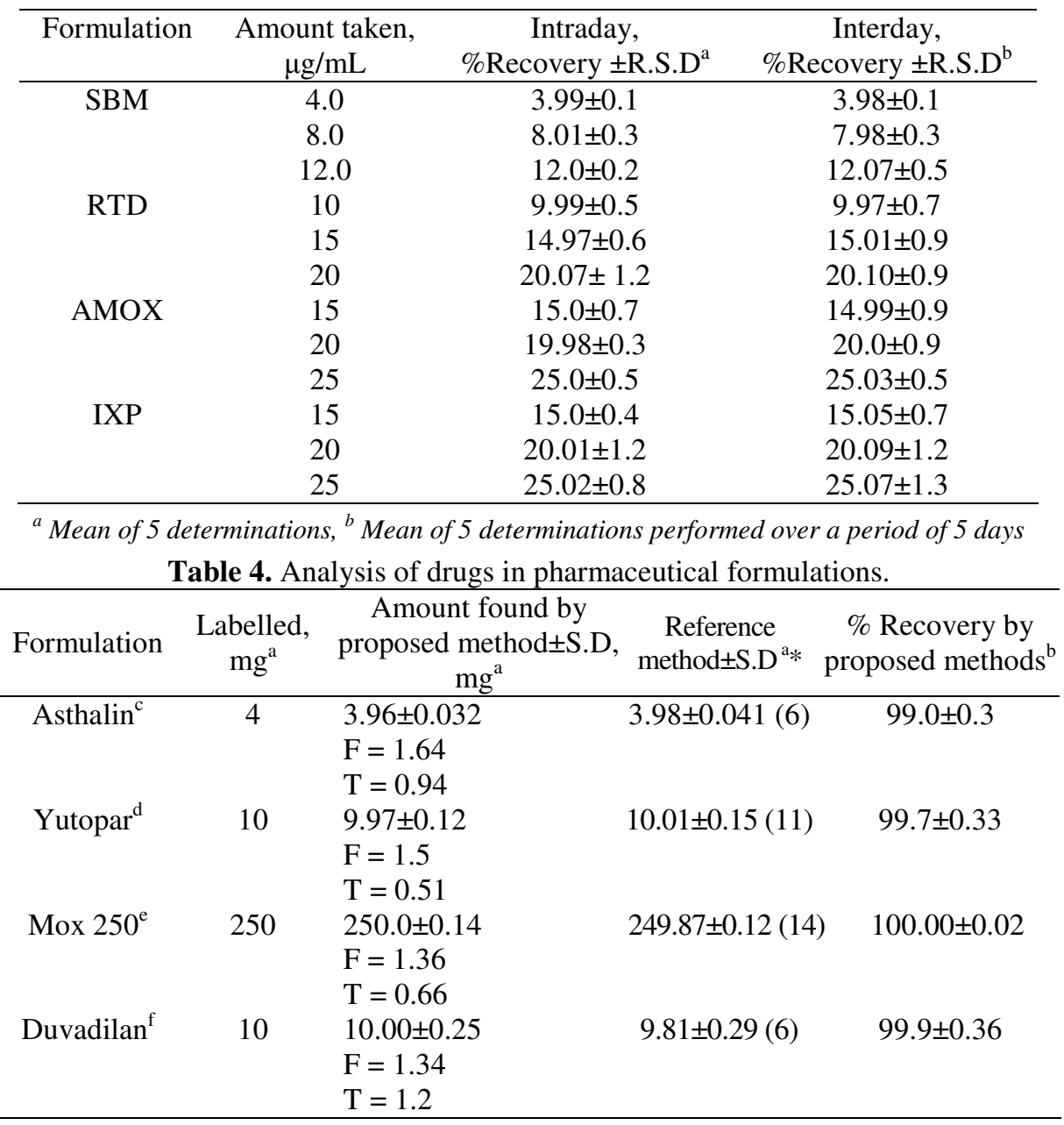

${ }^{a}$ Average \pm standard deviation of six determination; the $t$ - and $F$ - values obtained after comparison to the reference methods have following theoretical values at $95 \%$ confidence limit; $t=2.44 F=5.05,{ }^{b}$ After adding four different amounts of pure drugs to the fixed concentration of preanalysed pharmaceutical formulations, ${ }^{c} S B M$ equivalent to $4 \mathrm{mg} / \mathrm{tablet}$ (Cipla, India), ${ }^{d} R T D$ equivalent to $10 \mathrm{mg} /$ tablet (Alimbic, India), ${ }^{e} A M X$ equivalent to $250 \mathrm{mg} /$ Capsule (Ranbaxy, India), ${ }^{f} I X P$ equivalent to $10 \mathrm{mg} /$ tablet Tablet (Duphas Interfran, India)*References inside the bracket indicated reported methods given under references.

\section{Conclusion}

We have proposed a new spectrophotometric method for the determination of phenolic drugs, which is fairly sensitive, simple, and economical with reasonable precision and accuracy. The optical parameters and statistical comparison justify this method for application in routine drug estimation in pure and dosage forms. Also, the procedures do not involve any critical reaction conditions or tedious sample preparation steps. So, the recommended method is well suited for the assay and evaluation of drugs in pharmaceutical preparation and can also be considered as a general method for the quantification of phenolic drugs. 


\section{Acknowledgment}

One of the authors Ashwinee Kumar Shrestha thanks the Jawaharlal Nehru Memorial Fund, India (Ref: SU/2/552/2008-09/760) for providing scholarship and University of Mysore for providing facilities for the investigation.

\section{References}

1. Basavaiah K, Somashekar B C and Ramakrishna V, Acta Pharm., 2007, 57, 87.

2. Somashekar B C and Basavaiah K, J Anal Chem., 2007, 62, 432.

3. Mohamed G G, Khalil M S, Zayed M A and El-Shall A H M, J Pharm Biomed Anal., 2002, 28, 1127.

4. Dave H N, Mashru R C and Thakkar A R, Anal Chim Acta., 2007, 597, 13.

5. Rathore Y K S, Murugesan N, Mathur S C, Kumar Y and Sethi P D, Indian J Pharm Sci., 1993, 55, 206.

6. Bakry R S, El Walily A F and Belal S F, Anal Lett., 1995, 28, 2503.

7. Sastry C S P, Cintalapati R, Prasad A V S S and Sastry B S, Talanta, 2001, 53, 907.

8. Revanasiddappa H D and Manjula B, Il Farmaco, 2001, 56, 6159.

9. Bakry R S, El Walily A F M and Belal S F, Anal Lett., 1996, 29, 409.

10. Naidu G K, Suvardhan K, SureshKumar K, Rekha D, Sartry B S and Chiranjeevi P, $J$ Anal Chem., 2005, 60, 822.

11. Nagaraja P, Sunitha K, Vasantha R and Yathirajan H, Turk J Chem., 2002, 26, 1.

12. Revansiddappa H D, Manjula B and Ramappa P G, Anal Sci., 1999, 15, 661.

13. El-Shafie F S, Gad-Kariem E A, Al-Rashood K A, Al-Khamees H A and El-Obeid H A, Anal Lett., 1996, 29, 381.

14. Li Q and Yang Z, Anal Lett., 2006, 39, 763.

15. Mohamed G G, J Pharm Biomed Anal., 2001, 24, 561.

16. Al-Abachi M Q, Haddi H and Al-Abachi A M, Anal Chim Acta, 2005, 554,184.

17. El-Enany N, Belal F and M Rizk M, Il Farmaco, 2002, 57, 641.

18. Beyene N W, Staden J FV, Stefan R I and Aboul-Enein H Y, Il Farmaco, 2005, 60, 613. 


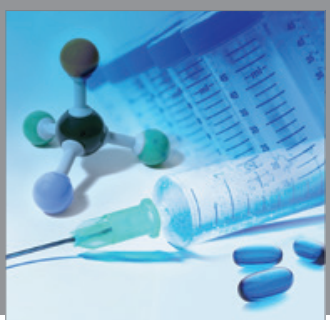

International Journal of

Medicinal Chemistry

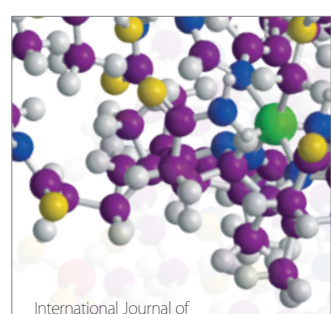

Carbohydrate Chemistry

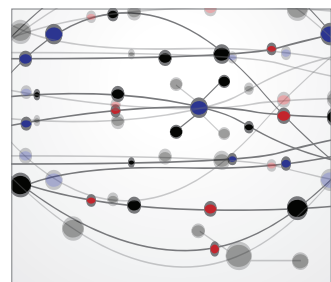

The Scientific World Journal
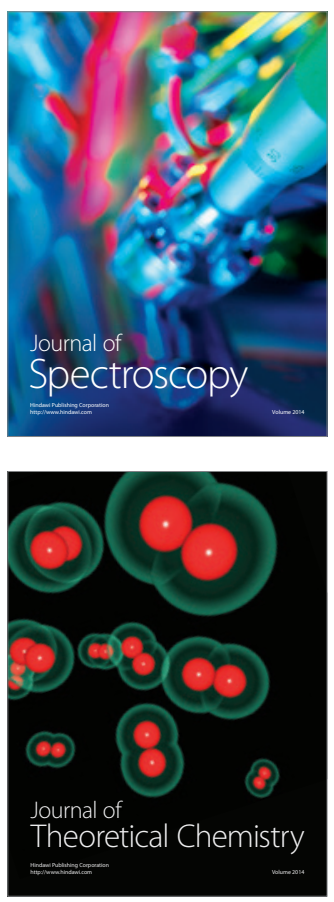
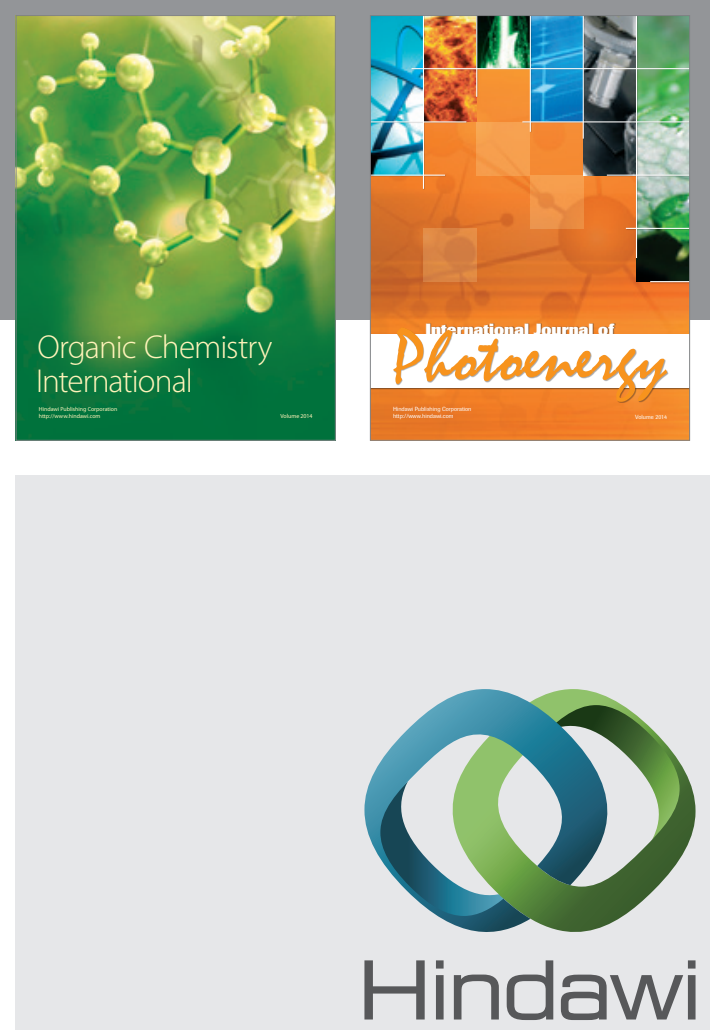

Submit your manuscripts at

http://www.hindawi.com
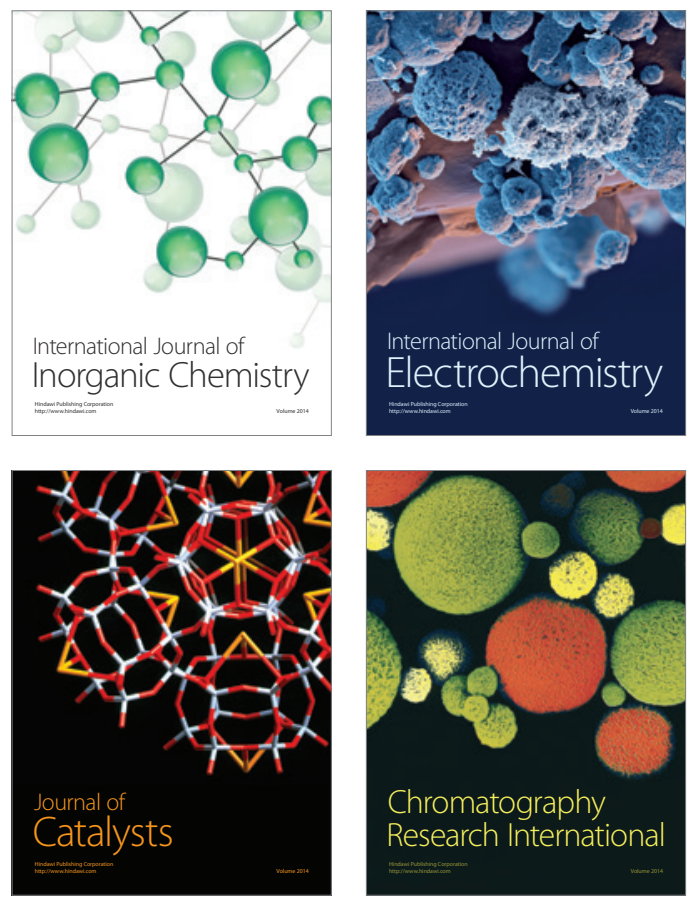
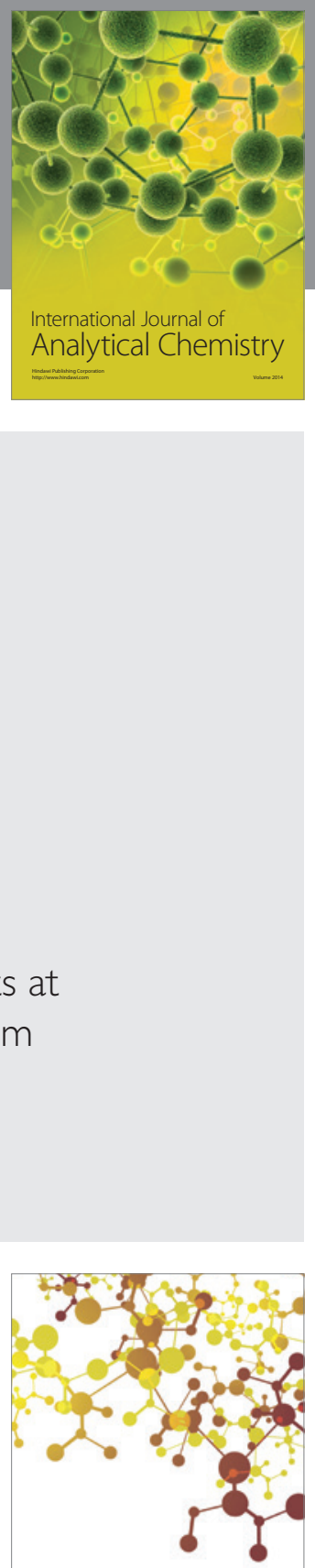

Journal of

Applied Chemistry
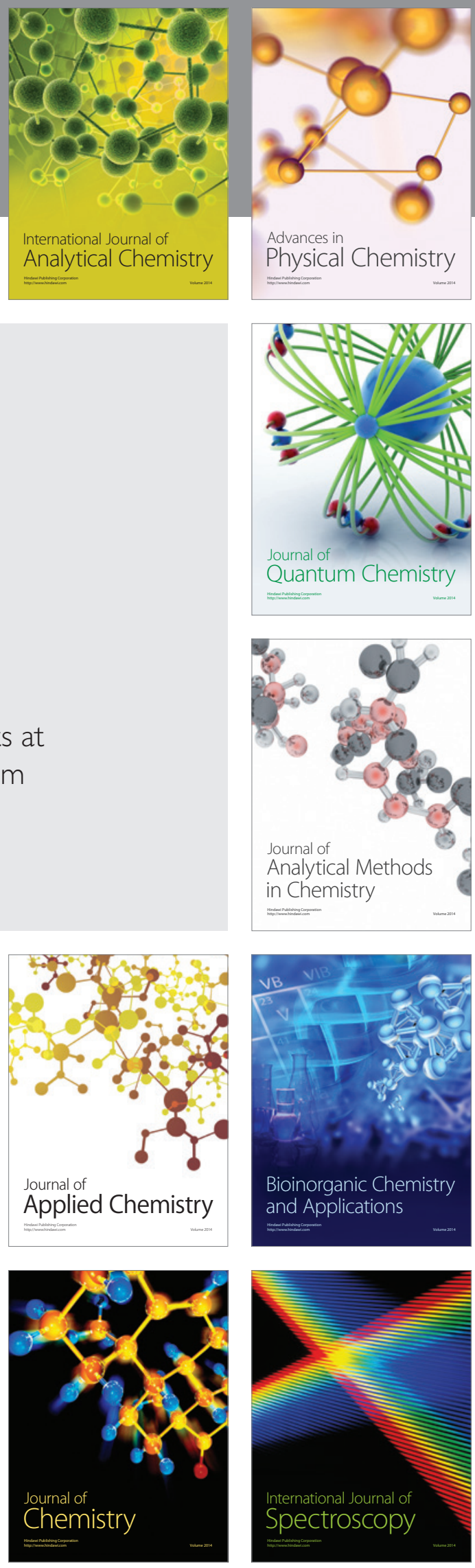